\title{
LA CONTRIBUCIÓN DE VINTILĂ HORIA A LA FILOSOFÍA DE LOS DERECHOS HUMANOS
}

\section{Carlos Ruiz Miguel**}

Fecha de recepción: 9 de agosto de 2016

Fecha de evaluación: 20 de marzo de 2017

Fecha de aprobación: 16 de mayo de 2017

Artículo de reflexión

DOI: http://dx.doi.org/10.18359/prole.3044

Forma de citación: Ruiz, C. (2017). La contribución de Vintilă Horia a la filosofía de los derechos humanos. Revista Prolegómenos Derechos y Valores, 20, 40, 113-125. DOI: http://dx.doi.org/10.18359/prole.3044

\section{Resumen}

Este artículo explora un aspecto de la obra de Vintilă Horia no estudiado hasta ahora: su filosofía de los derechos humanos. A pesar de que la primera formación universitaria de Horia fue jurídica, su trabajo se decantó por la vía de la literatura y de la filosofía mayormente. La idea de libertad será central en la primera etapa de su obra enfocada desde la perspectiva de las "ciencias humanas". En su segunda etapa, "holística", la libertad seguirá siendo el eje de su reflexión, pero desde una mirada que integra también las "ciencias naturales". Su aproximación "holística" a la cuestión de la libertad desembocará en una reflexión sobre los derechos humanos de acuerdo con la cual el verdadero "defensor" de los mismos no es el Estado, sino alguien que está fuera y tiene una especial capacidad para captar la esencia de lo humano y los peligros que la amenazan: el novelista.

\section{Palabras clave:}

Derechos humanos, filosofía, literatura, indeterminismo, libertad.

Este artículo es resultado de investigación que el autor ha realizado en la línea en derechos fundamentales en el ejercicio de su actividad investigativa universitaria.

* Catedrático de Derecho Constitucional, Universidad de Santiago de Compostela (Santiago de Compostela, España). Correo electrónico: carlos.ruiz@usc.es 


\title{
VINTILA HORIA'S CONTRIBUTION TO THE HUMAN RIGHTS PHILOSOPHY
}

\begin{abstract}
Summary
This article explores an aspect of the Vintila Horia's literary work that has not been studied yet, which is his philosophy about human rights. Although initially Horia had a legal academic formation, his work was mainly carried out on the literature and philosophy fields. The notion of freedom will be the core on the first stage of his work, focused from a human sciences perspective. On its second phase, "holistic", freedom will continue to be the core of his reflection, but from a perspective that also incorporates the natural sciences. Its "holistic" approach on the issue of freedom will lead to a reflection over human rights. However, their protector is not the state, but somebody else from the outside, whom has the ability to perceive the human essence and the dangers that threaten them; the novelist.
\end{abstract}

\section{Keywords:}

Human rights, philosophy, literature, indeterminism, freedom.

\section{A CONTRIBUIÇÃO DE VINTILA HORIA PARA A FILOSOFIA DOS DIREITOS HUMANOS}

\begin{abstract}
Resumo
O presente trabalho aborda um aspecto do trabalho de Vintila Horia não estudado até agora: sua filosofia dos direitos humanos. Embora a primeira formação universitária de Horia fosse jurídica, sua obra optou por o caminho da literatura e da filosofia em sua maioria. A ideia de liberdade é central para a primeira fase da sua obra focada desde a perspectiva das "ciências humanas". Em sua segunda fase, "holística", a liberdade continuará a ser o centro da sua reflexão, mas a partir de uma perspectiva que também integra as "ciências naturais". Sua aproximação "holística" para a questão da liberdade levará a uma reflexão sobre os direitos humanos de acordo com a qual o verdadeiro "defensor" dos mesmos não é o Estado, senão alguém que está fora e tem uma habilidade especial para capturar a essência do humano e os perigos que a ameaçam: o romancista.
\end{abstract}

\section{Palavras-chave:}

Direitos humanos, Filosofia, Literatura, Indeterminismo, Liberdade.

\section{Introducción}

Este trabajo pretende destacar la relevancia de la contribución de Vintilă Horia a la filosofía de los derechos humanos. Para ello, en primer lugar, recordaré su formación y titulación jurídica que determinará que obtuviera un doctorado en Derecho con un tema en el que profundiza, precisamente, esa filosofía (A). El pensamiento literario y filosófico de Vintilă desde 1959 va a dedicar a la idea de libertad reflexiones sumamente valiosas desde el ámbito de las ciencias humanas (B). Una década después, en 1969, Horia dirige su preocupación por la libertad con un tratamiento mucho más amplio, no solo ya desde el ámbito de las ciencias humanas, sino también desde el de las ciencias naturales (C).

El resultado de este proceso es una tesis doctoral defendida en 1980 (y publicada en 1981) que 
ofrece una perspectiva nueva a la filosofía de los derechos humanos como resultado de la aplicación tanto de sus conocimientos históricoculturales, cuanto de las nuevas técnicas epistemológicas que desarrolló en la década anterior; un enfoque que atribuye a la novela la capacidad de advertir al ser humano sobre los riesgos que pesan sobre él (D). Ahora bien, esa capacidad de advertencia, no la tiene cualquiera, sino quien posee el "genio" que solo surge donde hay libertad.

\section{A. Vintilă Horia: literato y pensador con formación jurídica}

Vintilă Horia (18 de diciembre de 1915-4 de abril de 1992) es un egregio escritor hispanorumano ${ }^{1}$ que destaca en el campo de la literatura y de la filosofía. En el campo de la literatura su aportación ha sido especialmente brillante y reconocida por sus novelas (la mayoría escritas originalmente en francés, excepto Un sepulcro en el cielo, que para mí es su cima y que está escrita originalmente en español); su poesía, escrita en rumano, sin embargo no ha tenido tanto eco (quizá por falta de traducción).

En cuanto a su pensamiento especulativo, sus ensayos, la mayor parte de ellos escritos en español, han tenido una resonancia muy favorable; no obstante, sus diarios (de los que solo se han publicado dos volúmenes, uno traducido al francés y al español [Horia, 1967] y el otro publicado solo en rumano [Horia, 2015]), son menos conocidos. Por último sus ensayos en la prensa escrita (sobre todo la amplia producción que publicó en el desaparecido diario El Alcázar los últimos años de su vida, 1980-1992) y en otras revistas ${ }^{2}$ revelan una extraordinaria inte-

1 Vintilă Horia obtuvo la nacionalidad española por carta de naturaleza mediante decreto 2276/1972, de 21 de julio (Boletín Oficial del Estado, 29 de agosto de 1972).

2 Vintilă Horia realizó numerosas colaboraciones para la revista Nuestro Tiempo. También fundó y dirigió una importantísima revista cultural, Futuro Presente (1971-1978), aunque en la misma sus artículos fueron escasos. ligencia para la comprensión del mundo junto a su vastísima cultura, pero lamentablemente son ya de difícil consulta (salvo algunos pocos artículos de prensa que están siendo recuperados en un blog${ }^{3}$ ).

La formación académica de Vintilă Horia tiene una doble vertiente ${ }^{4}$. Se licenció en Derecho en la Universidad de Bucarest el 16 de septiembre de 1940. Ya mientras ejercía tareas diplomáticas en Italia y Austria (fue agregado cultural en la Embajada de Rumanía en Viena), realizó estudios de Filosofía y Letras en las universidades de Perugia y de Viena, pero no pudo terminarlos, pues antes fue recluido en un campo de concentración en 1944.

Lo cierto es que la obra (con la notoria excepción que luego se comentará) desarrollada en el exilio entronca más con su formación en filosofía y letras que con su formación jurídica. Obtendría el Diplôme de Licence-ès-Arts, el 3 de julio de 1979 de la Facultad de Letras-Letras Modernas del Instituto Católico de París en la Universidad Pontificia de París.

Sin embargo, ciertas circunstancias personales y profesionales le llevaron en su etapa de madurez a volver al derecho. En efecto, aunque Vintilă era profesor contratado en la Facultad de Ciencias de la Información de la Universidad Complutense de Madrid, no podía acceder a la cátedra (plaza de profesor funcionario) sin poseer el doctorado. A pesar de haber cursado estudios de filosofía y letras en Perugia y Viena no llegó a licenciarse en

\footnotetext{
3 Véase http://vintila.blogspot.com.es/

4 Falta una biografía completa y rigurosa de Vintilă Horia, aunque él dejó algunas pinceladas (interesantísimas) de su autobiografía (cfr. Horia, 1970, pp. 5-7; Horia, 1978, pp. 261-265). Entre lo que se ha publicado (sorprendentemente, siempre omitiendo esos pasajes autobiográficos citados supra), una de las biografías más completas se encuentra en Martínez Sobrino (2011). Este artículo ofrece numerosos datos aunque alguno inexacto: no parece que llegara a "compaginar su trabajo en la Facultad de Ciencias de la Información de la Universidad Complutense con el de catedrático de Literatura en la Facultad de Filosofía y Letras de la Universidad de Alcalá de Henares", pues parece que obtenido el segundo puesto no siguió en el primero.
} 
esta materia hasta 1979. Resultaba difícil (finales de los años setenta) emprender el doctorado en Filosofía y Letras no teniendo aún la Licenciatura en Letras, sino en Derecho, y por ello, cuando decidió doctorarse lo hizo en Derecho (materia en la que era licenciado). El director de su tesis fue Jaime Brufau Prats, catedrático de Filosofía del Derecho de la Universidad de Valladolid. Cómo conoció al profesor Brufau es algo que ignoro por completo. El hecho es que finalmente Horia se doctoró bajo su dirección en la Facultad de Derecho de la Universidad de Valladolid, con la que no había tenido previa relación académica, pero en la que a finales de los ochenta y comienzos de los noventa impartió varias conferencias invitado por la asociación "Europa". El 14 de marzo de 1980, obtiene el grado de doctor en Derecho con la calificación de "Sobresaliente cum laude".

Una vez obtenido su doctorado, el 2 de diciembre de 1980 la Dirección General de Ordenación Académica y Profesorado autoriza a la Universidad de Alcalá la contratación de Vintilă Horia como profesor catedrático de Literatura Universal Contemporánea para el curso 19801981. Allí seguiría siendo catedrático hasta su jubilación. Fue docente en otras universidades y tras jubilarse siguió impartiendo clases en centros privados en Madrid.

El hecho de que tuviera una necesidad profesional de doctorarse le obligó a volver al derecho. Vintilă Horia haría de la necesidad virtud con su tesis doctoral, luego publicada, sobre Los derechos humanos y la novela del siglo XX. En esta obra, en la que cristaliza la sabiduría acumulada en los decenios anteriores (en especial el último), ofrecerá una perspectiva nueva para el estudio de la novela y de los derechos humanos.

\section{B. La libertad, núcleo de la reflexión filosófica y literaria de la obra vintiliana}

Se ha comentado con razón que la idea de "exilio" que marcó la biografía de Vintilă Horia también atraviesa toda su obra. Pero a veces esta observación lleva a dejar de lado la relevancia de la idea de "libertad". A mi juicio, la gran preocupación de la obra de Vintilă Horia es el ser humano. La vida y la libertad humana son el móvil de su obra literaria o ensayístico-filosófica.

La idea de la libertad se halla presente, prácticamente, desde el inicio de su trabajo filosófico. Aunque su primer libro de ensayo publicado en España se dedica al estudio del mito (Horia, 1956), su segundo trabajo teórico (un breve folleto que recoge una conferencia), se concentra ya en la idea de libertad (Horia, 1959) ${ }^{5}$. En este texto, Vintilă indica que para el ser humano toda la vida es poesía y todo es religión. Ambos planos no se confunden, sino que explican la doble dimensión del hombre: el que ha de salvarse aquí y ahora, defendiendo su libertad, amenazada de ver sometido su pensamiento; y el que dispone su salvación eterna mediante la religión (Horia, 1959).

El tercer libro de ensayo de Horia, publicado el mismo año que su gran novela sobre el exilio de Ovidio, y centrado en la figura del escritor rebelde (Horia, 1960a) ${ }^{6}$, una idea muy influida por la obra de Jünger $(1951)^{7}$, no podía dejar de volver al tema de la libertad. En este ensayo examina la actitud de los escritores del periodo soviético para demostrar "la firme actitud de una élite intelectual, ante la tentativa del conformismo oficial de destrozar al hombre y de acabar con su libertad" (Horia, 1960a, p. 135). En ese documento también expresa un pensamiento que se reiterará en su obra, a saber, que el Romanticismo constituyó una época de recuperación de la civilización europea y, a ese respecto, dice que "el respeto para con la persona humana llegó entonces en su apogeo,

5 Esta publicación alberga una conferencia pronunciada en el Ateneo de Madrid el 19 de mayo de 1959. Estudia este trabajo Pascucci (1968).

6 Hay una reedición veinte años más tarde (Horia, 1980) en la que se cambia el título del texto y se añaden algunos datos, además de un nuevo capítulo ("IX. El rostro de la disidencia").

7 En las páginas 16 y 22 a 25 del "Prólogo sobre el anticonformismo" de Horia (1960a) hay una referencia expresa a este trabajo de Jünger. 
y también la libertad de expresión" (Horia, 1960a, p. 13) ${ }^{8}$.

La obra literaria de Vintilă Horia nos muestra diversas aproximaciones a la idea de libertad: el exilio y la resignación.

La aproximación a la idea de libertad a través del exilio se halla en su primera gran novela, la dedicada a Ovidio, publicada también en 1960 (Horia, 1960b). Se suele comentar que esta novela tiene como centro la reflexión sobre el exilio, pero se olvida que este es la consecuencia de la pérdida de la libertad ("hemos perdido toda libertad y basta una palabra, murmurada por un esclavo al oído de un policía, para perder tanto los bienes como la vida" [Horia, 1960b, p. 151]). $Y$ es que, en efecto, "la libertad se paga cara, pero merece la pena pagar ese precio" (Horia, 1960b, pp. 74-75). Es en el exilio donde Ovidio encuentra la libertad: "Si el deseo de vivir en libertad puede más en usted que la esperanza de volver a Roma, no vacile en emprender de nuevo el camino del Arroyo Salado" (Horia, 1960b, p. 230).

El acercamiento a la idea de libertad se hace también a partir de la idea de resignación en su siguiente novela, de 1961, una "historia del bosque rumano y de la libertad" en palabras del autor en la dedicatoria que me hizo de su libro. En la dedicatoria impresa Vintilă ofrece su novela "A los habitantes de mi bosque, los cuales, en nombre de los hombres, se resignan a la libertad" (Horia, 1961), a lo que sigue una expresiva cita de Kierkegaard "El caballero de la resignación renuncia al logro completo y se inclina con toda humildad ante el poder eterno. Es su libertad" (Horia, 1961, pp. 7-8).

Bien es cierto que muchos pasajes de la obra tratan de la libertad de los pueblos, pero eso no significa que se olvide el tema de la libertad humana que tiene su fuente, precisamente, en la resignación:

$8 \quad$ El pasaje de la edición de 1980 (p. XII) corrige la redacción y dice "el respeto para con la persona humana llegó entonces en su apogeo".
Había, pues, que resignarse. Era la única salida hacia la libertad entre los límites que imponía esta breve servidumbre situada entre el nacimiento y la muerte [...]. Sí, esto era lo único que le quedaba por hacer. Renunciar a su sueño de sabiduría y de inmortalidad, resignarse sin maldecir, combatir junto a sus campesinos para que el bosque siguiera alimentando la esperanza en el corazón de los esclavos [...] ¿No era esta acaso la única libertad permitida al hombre en medio de las leyes que del hombre hacen un cautivo arrojado al fondo de las tinieblas? (Horia, 1961, pp. 186-187).

Vintilă Horia, de algún modo, sintetizará estas dos vías en un pasaje de su tercera novela de los años sesenta, Los imposibles, donde dice que "el hombre no puede elegir la libertad más que en sí mismo, huyendo de un país a otro, o conociéndose cada vez más y reculando hacia sus propias profundidades como un cangrejo" (Horia, 1962, pp. 43-44).

La siguiente novela de Horia, La séptima carta, sobre Platón, constituye el fin de una primera etapa en su obra y el inicio de la fase que desarrollará años después. En esta novela, que debe leerse conjuntamente con un valiosísimo opúsculo filosófico que escribió sobre el mismo asunto que trata su novela, Vintilă Horia va a prefigurar una tesis que luego ampliará en su etapa holística y que es muy importante para entender su ulterior reflexión sobre los derechos humanos: la de que el presupuesto de la crisis es una escisión.

Dice el autor que en la época de Platón, "como en todo proceso de descomposición", asistimos "a una separación cada vez más acentuada entre lo divino y lo humano, a un desbordamiento de este sobre aquel" de suerte que la "decadencia religiosa (lleva) detrás de sí el cadáver de la decadencia política" (Horia, 1964b, p. 8). Y observa que "el tiempo de todas las juventudes está hecho de encuentros milagrosos; el de la vejez de separaciones profanas" (Horia, 1964a, p. 293). De este modo "la pérdida de 
la fe" es la causa del "final de ciclo" (Horia, 1964a, p. 63).

En un contexto así, los dirigentes "gobernaban con ayuda de la mentira, creyendo salvar con pequeños éxitos un conjunto podrido en su base a causa de un crimen original" (Horia, 1964a, p. 136). Y añade, siguiendo a Paul Hazard, que el principio de la descomposición occidental se produce a fines del siglo XVII cuando la intelectualidad europea:

[...] se aleja decididamente de los valores digamos tradicionales o religiosos y acepta como norma artística y como ley de vida cotidiana la depreciación de los valores supremos de los que habla Heidegger. La libertad del individuo coincidió, pues, con la negación de todos aquellos valores que Platón quiso salvar, que fueron reconocidos como tales por el cristianismo, que dieron al concepto de areté un nuevo empuje durante el Renacimiento y que perecieron bajo el alud de falsos atrevimientos llamado progreso (Horia, 1964b, p. 23).

En la reflexión filosófica sobre su propia novela, Vintilă teoriza sobre la virtualidad de la novela como técnica de conocimiento avanzando ideas que madurará una década después. Dice que "una novela fiel al concepto de areté" puede

[...] dar cuenta de la totalidad del fenómeno Platón, en el sentido de que la vida y obra, todo lo que la exégesis filosófica o la simple biografía ignoran recíprocamente, solo la novela es capaz de presentarlo bajo una luz de unidad (Horia, 1964b, p. 25).

\section{De las ciencias humanas a las ciencias naturales: la comprensión holística de la libertad}

Es el propio Vintilă Horia quien confiesa que es a partir de 1969 cuando amplía de forma decisiva el horizonte de sus preocupaciones (Horia,
1986) ${ }^{9}$. Se inicia su etapa holística, también en otros aspectos, metapolítica. Si hasta ahora había empleado sus talentos en profundizar en el arte y en la filosofía, una serie de circunstancias hará que empiece a tomar contactos con otras ramas del saber. Se comienza así su etapa "holística". Esta nueva fase aparece marcada por cuatro hitos: primero, la dirección de la colección Punto Omega (1966-1969); segundo, la preparación y publicación de su obra Viaje a los centros de la Tierra (1970, 1971); tercero, la elaboración de su Encuesta detrás de lo visible (1975); y cuarto, la fundación y dirección de la revista Futuro Presente (1971-1976).

Sus frutos se traducirán, al margen de numerosos y brillantes artículos de prensa, en varios libros fundamentales: Viaje a los centros de la Tierra (1971), Introducción a la literatura del siglo XX (1976), Consideraciones sobre un mundo peor (1978) y Los derechos humanos y en la novela del siglo XX (1981).

\section{a. Los cuatro hitos del tránsito a la fase holística de Vintilă Horia}

El primero de los hitos que señalan el tránsito hacia la fase holística del pensamiento vintiliano lo marca la designación de Vintilă Horia como director de la colección Punto Omega de la editorial Guadarrama en la segunda mitad de los años sesenta (1966-1969). Como dice Horia, gracias a esa colección se fueron

9 En este artículo Vintilă dice: "me parece satisfactorio, desde un punto de vista personal, el que miembros de la Unesco y de la Fundación Cini, veneciana también, reunidos en la ciudad de Tiziano y de los dogos, hayan llegado en 1986 a las conclusiones a las que el autor de estas líneas llegó, año tras año y libro tras libro, desde 1969 a esta parte. No voy a pecar por modestia ni por su contrario, pecados intelectuales en sus insoportables excesos, afirmando que no tuve día ni noche de descanso, durante casi dos decenios, al constatar el desnivel existente entre los avances de la ciencia, y especialmente de la física, y el empeño de la política, como de la ciencia política, en seguir aplicando a la humanidad fórmulas y tácticas pertenecientes al siglo pasado". 
[...] revelando al público español libros fundamentales como los de Jean Charon, Stéphane Lupasco, Pascual Jordan, Weizsäcker, Jacques Rueff, Jules Monnerot, Pierre de Boisdeffre y muchísimos más que hicieron de aquella colección y en poco tiempo la más prestigiosa representación de la reforma espiritual, en sentido contrarrevolucionario, que se estaba produciendo en el mundo bajo el impacto, por un lado, de la nueva ciencia, $y$, por el otro, de una literatura, una filosofía y una crítica literaria que nada tenían que ver con los decadentes mausoleos leninistas del realismo seudosocialista (Horia, 1984).

En esos años disminuirá el ritmo de sus propias publicaciones $y$, de hecho, si en la primera mitad de los sesenta publicó cuatro novelas, en la segunda mitad solo publicó una (Una mujer para el Apocalipsis), que apareció precisamente en la colección Punto Omega en 1968. En un pasaje de esta novela se aprecia ya cómo Vintilă ha empezado a profundizar en el estudio de la física cuántica que abrirá nuevos horizontes a su pensamiento (Horia, 1968).

El segundo hito, y a mi entender el más importante, lo signa la preparación y publicación en 1971 de una obra esencial en el pensamiento vintiliano: su Viaje a los centros de la Tierra. Este "viaje" fascinante e iniciático fue posible gracias a Enrique Costas Lombardía, director de la publicación Tribuna Médica que fue quien encargó a Vintilă la realización de las entrevistas que componen el "Viaje". En la "Nota preliminar" al Viaje... se realizan ya afirmaciones que resultan claves para entender el pensamiento holístico de Vintilă Horia:

[...] sigue siendo la filosofía la manera o la técnica más adecuada para explicar lo que sucede con el hombre en general y con nuestros contemporáneos en particular [...]. Pero también iremos a visitar a algún científico, a algún filósofo de las ciencias, a algún médico famoso, a algún industrial con capacidad para filosofar, a algún ci- neasta, a algún historiador y ¿por qué no? a algún físico y a algún novelista. Todas las actividades constituyen medios para otorgar al hombre el dominio del mundo exterior, pero también sobre sí mismo, y todas las disciplinas actuales, todas las técnicas del conocer, tratan hoy de elaborar un lenguaje común, de inventar un terreno intermedio donde poder alcanzar un vocabulario general, un pacto entre las sabidurías, que hagan posible otra vez un entendimiento total del hombre (Horia, 1971, p. 8).

$\mathrm{Y}$ es que, como sostiene el autor al final de esta "Nota",

Espero, además, que el lector pueda formarse una idea total y sintetizadora acerca de las artes y disciplinas que hoy mueven el mundo, con el fin de poder comprender, una vez cerrado el libro, que la Verdad es una y que solo difieren nuestras técnicas para acercarnos a ella (Horia, 1971, p. 12).

La Encuesta detrás de lo visible sería el tercer hito que jalona el proceso de formación del pensamiento holista de Vintilă Horia. Igual que el Viaje..., esta Encuesta... fue posible gracias a Enrique Costas Lombardía, que, como ocurrió con el Viaje... encargó a Vintilă la ejecución de las entrevistas que forman esta Encuesta ... para su publicación en la citada revista. La Encuesta... de 1975, podríamos decir, empieza allí donde termina el Viaje... Si esta última obra finalizaba con varias entrevistas a médicos sobre el cerebro o los efectos de las drogas en la psique, la Encuesta... va a intentar ir más allá de la psicología para adentrarse en la parapsicología.

Nuevamente la "Introducción" de la obra nos ofrece las claves de la misma. Allí dice Vintilă que "pasar del esoterismo a la física nuclear no resulta ilícito y tampoco desprovisto de posibilidades de reflexión lógica" (Horia, 1975, p. 15). En dicha "Introducción" Horia hace una referencia a una idea ya expresada por el sociólogo Simmel que coincide con las premisas de las que parte nuestro autor: 
El sociólogo Georg Simmel había escrito este pensamiento hace ya varios decenios dando cuenta de la restricción fundamental de las ciencias: "Cada vez que una ciencia particular trata de formular respuestas universalmente verdaderas, respuestas, sobre todo, a las preguntas fundamentales referentes al hombre, al Universo, se sale de su propio cauce y terrenos y se va por las ramas".

Para que esto no suceda, cada ciencia particular se encuentra hoy en la obligación de unir sus esfuerzos con los de las disciplinas que enfocan el tema del hombre y del Universo como método y fin. [...] El alma [...] es algo que lo une (al hombre), al mismo tiempo a la vida terrenal y a la promesa inquietante del más allá. En este sendero de dos carriles es en el que me he esforzado en mantener mis caballos a lo largo de este nuevo viaje (Horia, 1975, pp. 16-17).

El cuarto hito está señalado con la fundación y dirección de la revista Futuro Presente (subtitulada "Revista mensual de cibernética y futurología") que llegó a publicar 41 números (1971-1978), una revista que no tiene parangón en España cuarenta años después. Ciertamente, Horia publicó pocos artículos en esa revista que dirigía (algunos luego reproducidos en Consideraciones sobre un mundo peor), pero continuó allí la tarea que había emprendido en su Viaje a los centros de la Tierra no solo publicando entrevistas a representantes señeros del pensamiento y la ciencia contemporáneos, sino dando a conocer al público español artículos de los pensadores más brillantes de las ciencias humanas y naturales.

Llama poderosamente la atención que en este proceso en el que Horia dota de mayor completitud a su aproximación a la realidad humana estuviesen ausentes los juristas (también los teóricos de la política).

\section{b. Los frutos del nuevo enfoque holístico del pensamiento vintiliano}

Los frutos del nuevo enfoque holístico del pensamiento vintiliano serán, aparte del Viaje..., tres obras importantísimas ya mencionadas: Introducción a la literatura del siglo XX; Consideraciones sobre un mundo peor y Los derechos humanos y la novela del siglo XX. Me detendré brevemente en las dos primeras, dejando la última para un análisis separado.

Aunque publicada en 1978, Consideraciones sobre un mundo peor está formada, con la excepción del primero y de la mitad del último de los trece ensayos que la contienen, de textos ya publicados en diversas revistas o en conferencias pronunciadas entre 1970 y 1976, por lo que podría considerarse como una obra anterior a la Introducción a la literatura del siglo $X X$, aunque se haya editado después.

Es significativo que en este libro Vintilă Horia se separe del pensamiento de su admirado Giovanni Papini, formulando ideas que luego profundizará acerca del Renacimiento. Papini, según cuenta Horia en la obra dedicada a este autor, veía en el Renacimiento continuación del mensaje cristiano (Horia, 1965), una síntesis del misticismo medieval y del optimismo del mundo antiguo (Horia, 1965); sin embargo, en 1978, Horia, aunque no haga explícita esta disidencia, no comparte ese juicio y considera que el Renacimiento no era más que una imitación de lo que hicieron griegos y romanos.

La Introducción a la literatura del siglo XX es, sin duda, una de las obras más importantes del Vintilă Horia "teórico". No solo es ya un fruto maduro de la etapa "holística" del pensamiento vintiliano, sino que ofrece una de las más sugestivas y penetrantes visiones de la literatura del siglo XX nunca publicadas. Allí Vintilă formula una tesis cuya validez demuestra con los relucientes análisis de la literatura del siglo XX que realiza: 
Hemos llegado, pienso, a un punto favorable para la siguiente formulación, en relación directa con el propósito del presente libro: la literatura no es una actividad aislada, que formula a veces conceptos y juicios ajenos a las demás actividades del espíritu, sino que, al contrario, es una técnica del conocimiento -igual que la física, la biología, la astronomía, la psicología o la pintura- contemporánea de las demás gnoseologías.

\section{$[\ldots]$}

Y [...] la novela es el género literario que mejor condensa dicha contemporaneidad (Horia, 1976, p. 14).

El autor explica por qué la novela tiene, a su juicio, esa capacidad:

[...] una técnica de conocimiento puede aunar ciertos esfuerzos, con el único fin de ofrecer una imagen más correcta y completa del hombre que la de los siglos anteriores [...].

Esta técnica del conocer con posibilidades epistemológicas, en sentido más bien estético que científico, es la novela. La literatura en general, y la novela en especial podría ser el terreno más propicio para un acercamiento entre las diversas técnicas del conocimiento humano (Horia, 1976, pp. 16-17).

Esta idea quedará ya asentada en el pensamiento vintiliano. Así, en un texto de sus Consideraciones... y redactado después (la segunda parte del capítulo decimotercero de la obra) lo reiterará:

La novela es una técnica del conocer, la más completa, la única posibilidad de encerrar la realidad en una sola obra, más que la física, o la biología, o la música, la única verdaderamente capaz de describir un todo y de enseñar (Horia, 1978, p. 264).

\section{La reflexión vintiliana sobre los derechos humanos a la luz de su entendimiento holístico de la libertad}

Como se ha dicho en la primera parte de esta contribución, la reflexión de Horia sobre los derechos humanos es un ejemplo de cómo la necesidad se hizo virtud. A fin de poder ostentar una cátedra universitaria en la Universidad de Alcalá, Vintilă Horia precisaba de contar con el título de doctor, pero resultaba difícil doctorarse en Filosofía y Letras ya que, aunque había iniciado sus estudios en este terreno en 1941 no los concluyó hasta 1979. En consecuencia, la necesidad personal y profesional de obtener un doctorado tuvo que orientarse al derecho, saber en el que Vintilă se licenció en 1940.

Este es el origen de su tesis "Los derechos humanos y la novela del siglo XX" que obtuvo la máxima calificación en 1980 y se publicó al año siguiente. Dicho trabajo doctoral va a ser también una especie de autobiografía vital $e$ intelectual según palabras de Vintilă a quien esto firma. Aunque el autor divide su obra solo en capítulos, se perciben, claramente, tres partes. La primera es donde Horia sienta las bases de su teoría (capítulos I-IV, páginas 13125); la segunda es donde pone a prueba, con su espléndido conocimiento de la novela del siglo XX, la validez de su teoría (capítulos V-IX, páginas 127-223) y una última parte conclusiva (capítulo X, páginas 225-238).

a. La incongruencia de las premisas básicas de la teoría de los derechos humanos

La nueva visión sobre el Renacimiento (tan distinta de la que tenía Papini y que Horia asumió en su obra sobre el italiano de 1956) y el indeterminismo de la física cuántica en la que empezó a profundizar desde 1969, le llevaron a ver las premisas básicas sobre las que, incongruentemente, se apoyó la teoría de los derechos humanos. 
En primer lugar, para Vintilă Horia, "la aparición y proclamación de los derechos humanos está ligada a un sistema heredado del Renacimiento" (1981, pp. 45 y 234). Ahora bien, el afán de competir (y no ya colaborar) con Dios en la labor de modificación del mundo, considerado imperfecto y al que el hombre podría perfeccionar es un afán típicamente renacentista (Horia, 1981). Para Horia, la escisión establecida por Descartes entre la res cogitans (el sujeto) y la res extensa (el objeto) llevó a considerar que "los otros" son unos objetos que el sujeto puede transformar según sus deseos, y si el objeto no se aviene al proyecto del sujeto, la posibilidad de transformar el sujeto puede convertirse en castigo o incluso en eliminación (Horia, 1981), como ocurrió con el genocidio de la Vendée, justificado para "sellar para siempre los derechos de la humanidad" (Horia, 1981, p. 95).

Esta escisión cartesiana es el corolario de la separación, ruptura, que se produce en el Renacimiento entre el hombre y Dios, que tiene como efecto dejar al hombre con miedo a la soledad, lo que obligaba a precisar y definir unos derechos que antes estaban sobreentendidos. Si en las épocas medievales o románticas, de vuelta a Dios, la defensa del hombre estaba en Dios, en las épocas renacentistas o neoclásicas los derechos humanos aparecen como algo conseguido por el hombre en contra de sí mismo o de otros hombres (Horia, 1981). Y es que la aparición de las declaraciones de derechos humanos coincide con la conversión del Estado en Leviatán todopoderoso (Horia, 1981).

Además, Horia indica que la "formulación de los derechos humanos se hace en el marco de la filosofía y de la ciencia 'clásicas', que eran deterministas" (1981, pp. 51-52), lo que significa la imposibilidad de enfocar correctamente el concepto de libertad. Un ejemplo de ello es la filosofía de Holbach, que trata de extraer de la naturaleza (entendida de modo mecanicista y determinista) principios valederos para el ser humano (Horia, 1981). El resultado de este enfoque erróneo es que a medida que se proclaman derechos del hombre lo prohibido aumenta progresivamente y lo permitido se reduce (Horia, 1981).

El final del siglo XX ofrecía para Vintilă un panorama ante el que estaba "aterrorizado", a saber, una situación en la que al mismo tiempo que las Naciones Unidas hacen las más bellas declaraciones de derechos humanos: "el poder económico, unido al dominio de la técnica, controla hoy el poder político, desde una perspectiva humana más reducida aún y dentro de cuyo aislamiento casi ascético, pero en sentido invertido, ningún derecho humano puede sobrevivir" (Horia, 1981, p. 125).

b. Un nuevo paradigma para la fundamentación de los derechos humanos

En su lugar, el autor propone otra óptica, que es la del paradigma de Dios y del ser humano y de la nueva ciencia indeterminista, es decir, el paradigma de la libertad.

Por un lado, Vintilă parte de la premisa de que Dios es perfecto pero el hombre es imperfecto. De ahí que, siguiendo a Jünger, considere que situar, como pretenden algunas utopías, al hombre en un estado de "perfección", implica negar la naturaleza imperfecta del hombre, que no es sino el hecho de que por su libre albedrío tiene la posibilidad de caer en o elegir el error. Así, la "falta de peligro" derivada de la "seguridad" que pretenden algunas utopías e ideologías se convierte en un "peligro metafísico" que acabaría con la Historia, que no es sino el escenario de peligros (Horia, 1981).

A partir de ahí, inspirándose en santo Tomás de Aquino, Horia sostiene que a "más religión, más libertad" pues "menos religión, o sea, menos conciencia del pecado original, (significa) menos libertad en la medida en que la falta de religión o de conciencia religiosa trae consigo más autoridad y formas de Estado cada vez más autoritarias" (Horia, 1981, p. 153) ${ }^{10}$. La consecuencia clara para Horia, es que los "derechos sin libertad" (es

10 Aunque Horia no lo cita, ese pensamiento coincide con el de Juan Donoso Cortés y su teoría de las "dos represiones" en su Discurso sobre la dictadura (1848). 
decir, la proclamación de "derechos humanos" sin reconocer el libre albedrío) son "pura forma sin contenido" (Horia, 1981, p. 155). O dicho de otra manera, si negando la imperfección humana se diviniza al hombre este pierde sus "derechos" (Horia, 1981), lo cual es explicable, pues un dios no necesita "derechos". Si desaparece el "hombre", desaparecen sus derechos (Horia, 1981).

Por otro lado, Vintilă Horia concreta más al decir no solo que la premisa de una perspectiva correcta es la admisión de la perfección divina y de la imperfección del ser humano dotado de libre albedrío, sino que la religión que mejor expresa esa realidad es el cristianismo. Precisamente porque el cristianismo considera como dogmas de fe el "libre albedrío" y la imperfección del hombre necesitado de la ayuda divina (la gracia), es la única religión sobre la que se pueden formular unos "derechos humanos" con contenido. Y, al contrario, el humanismo renacentista y la revolución que han atacado frontalmente al cristianismo no permiten que los derechos humanos proclamados de palabra puedan hacerse realidad (Horia, 1981). Horia compara la idea de Toynbee de que una fe religiosa es el principio de toda civilización y el cristianismo es el principio de la civilización occidental. Dado que para Horia la idea de los derechos humanos surge en el marco del cristianismo, el debilitamiento u olvido de este supone un debilitamiento de aquellos, y al contrario, la mayor vitalidad del cristianismo significa una mayor vitalidad de esos derechos (Horia, 1981).

\section{c. La novela antideterminista del siglo $X X$ $y$ los derechos humanos}

En esa onda, la de la libertad, se sitúan los novelistas antideterministas del siglo XX, según la cual el otro no es un objeto, sino otro sujeto: no somos iguales, somos hermanos (Horia, 1981). El escritor puede ser "observador objetivo de la sociedad porque es observador objetivo de sí mismo" (Horia, 1981, p. 200). Y en ese escenario, el literato funge como auténtico defensor del ser humano (Horia, 1981). Ya en el Romanticismo Vintilă constata cómo el novelista romántico se erigirá en defensor de los débiles (Horia, 1981).

Pero el escritor, dice Horia, ha dejado de ser un simple literato o un humanista; se ha convertido en algo más: en el "representante de una totalidad". No defiende a una "clase social" o a una "categoría intelectual", sino "al Hombre en sí, víctima de unos instrumentos forjados a su favor desde el Renacimiento hasta hoy y transformados con el tiempo en armas letales" (Horia 1981) contra el propio ser humano. El enfocar los derechos humanos desde la perspectiva que los novelistas tienen del hombre como poseedor de unos derechos en peligro es, para Vintiă, "la única manera de llegar al mismo tiempo a un conocimiento auténtico del hombre y a una posible solución". Para él, ningún género literario, fuera de la poesía épica de la Grecia clásica, ha coincidido tanto con el destino del hombre en su trágica completitud como la novela del siglo XX (Horia, 1981).

Para tratar de demostrar su teoría, Horia examina las novelas y los autores que a lo largo del siglo XX se erigieron en defensores del ser humano: Kafka, Pasternak, Solzhenitsyn, Camus, Huxley, Orwell, Zamiatin, Witkiewicz, Hesse, Jünger, Unamuno, Graham Greene y Julien Green. ¿Cómo defiende la novela al ser humano? Para Horia, el novelista no hace profecías, sino advertencias (Horia, 1981) que se cumplirán o no de acuerdo con lo que libremente hagan los hombres.

\section{d. El novelista, profeta o genio}

En Los derechos humanos y la novela del siglo $X X$ se explica, sí, que la novela se halla en una posición privilegiada para advertir al ser humano, pero no se termina de explicar el por qué eso sucede. Las ideas de esta obra serán objeto de un desarrollo literario en una novela posterior, el siguiente libro de la bibliografía de Horia. En esa novela encontraremos una respuesta a la pregunta. Allí dice que "la 
religión debería manifestarse como lo hace el arte: a unos privilegiados que se encargarían de retransmitir el mensaje" (Horia, 1983, p. 150). La novela vendría a ser el oráculo del siglo XX.

A la postre, Horia, aunque no lo diga así, confía en el "genio". El genio es esa luz superior que ilumina las mentes no solo para ver, sino para hacer ver, lo que el resto no ve. Y el genio, por definición, es algo imprevisible e indeterminado. Es un regalo que se hace a un ser predispuesto a recibirlo porque goza de libertad.

\section{Conclusión}

La contribución de Vintilă Horia a la filosofía de los derechos humanos es importante y original. Su acercamiento holístico al estudio de los derechos humanos permite identificar los condicionamientos que impiden su pleno desarrollo y cumplimiento así como quiénes son los "guardianes" más idóneos de los mismos. Horia demuestra que un pensamiento anclado en premisas y en un marco determinista y que no parta de una concepción correcta del hombre como ser libre, pero "humano" y no divino, resulta contradictorio con la idea de derechos humanos y lastra su desarrollo. Así mismo, considera que los novelistas del siglo $\mathrm{XX}$, precisamente por partir de la premisa adecuada, han sido los auténticos "custodios" del ser humano y de sus derechos.

\section{Referencias}

Boletín Oficial del Estado, 29 de agosto de 1972.

Donoso, J. (1849). Discurso pronunciado en el Congreso el 4 de enero de 1849. En: Obras de Don Juan Donoso Cortés (pp. 87-90). Madrid: Sociedad Editorial de San Francisco de Sales.

Horia, V. (1956). Presencia del mito. Madrid: Escelicer.

Horia, V. (1959). Poesía y libertad. Madrid: Ateneo.
Horia, V. (1960a). La rebeldía de los escritores soviéticos. Madrid: Rialp.

Horia, V. (1960b). Dieu est né en l'exil. París: Fayard.

Horia, V. (1961). Le chevalier de la résignation. París: Fayard.

Horia, V. (1962). Les impossibles. París: Fayard.

Horia, V. (1964a). La septième lettre. París: Plon.

Horia, V. (1964b). Platón, personaje de novela. Madrid: Nacional.

Horia, V. (1965). Giovanni Papini. Madrid: Escelicer.

Horia, V. (1967). Journal d'un paysan du Danube. París: La Table Ronde.

Horia, V. (1968). Une femme pour l'Apocalypse. París: Julliard.

Horia, V. (1970). El hombre de las nieblas. Barcelona: Plaza \& Janés.

Horia, V. (1971). Viaje a los centros de la Tierra. Barcelona: Plaza \& Janés.

Horia, V. (1975). Encuesta detrás de lo visible. Barcelona: Plaza \& Janés.

Horia, V. (1976). Introducción a la literatura del siglo XX. Madrid: Gredos.

Horia, V. (1978). Consideraciones sobre un mundo peor. Barcelona: Plaza \& Janés.

Horia, V. (1980). Literatura y disidencia. De Mayakouski a Soljenitsin. Madrid: Edica.

Horia, V. (1981). Los derechos humanos y la novela del siglo XX. Madrid: Magisterio Español.

Horia, V. (1983). Perseguid a Boecio. Madrid: Dyrsa.

Horia, V. (1984). Recuerdo de Andrés Bosch y de otras genialidades. El Alcázar, febrero. Disponible en: http://vintila.blogspot. com.es/2007/12/recuerdo-de-andrsbosch-y-de-otras.html 
Horia, V. (1986). Comentario muy personal a la "Declaración de Venecia". El Alcázar, 5 de junio. Disponible en: http://vintila. blogspot.com.es/2009/02/comentariomuy-personal-la-declaracion.html

Horia, V. (2015). Memoriile unui fost sagetator. Bucarest: Vremea.

Jünger, E. (1951). Der waldgang. Fráncfort del Meno: Vittorio Klostermann.
Martínez, A. (2011). Las Tristes de Ovidio a través de Dios ha nacido en el exilio. Diario de Ovidio en Tomis de V. Horia. Myrtia, 26, pp. 289-312.

Pascucci, L. (1968). El tema de la libertad en los escritores rumanos contemporáneos. Revista de Estudios Políticos, 157, pp. 161-168. 